\title{
Relationship between production conditions and milk gross composition in ewe's and goat's organic and conventional farms in central Greece
}

\author{
Eleni Malissiova ${ }^{1,2}$ - Athina Tzora $^{3}$ - Antonios Katsioulis ${ }^{1}$. \\ Marina Hatzinikou ${ }^{1}$ - Andreas Tsakalof ${ }^{1}$ • Ioannis S. Arvanitoyannis ${ }^{4}$. \\ Alexander Govaris ${ }^{5}$ - Christos Hadjichristodoulou ${ }^{1}$
}

\begin{abstract}
Organic milk and dairy products are widely consumed lately, with the belief they are of higher nutritional quality than conventional, while researchers report contradictory views on this issue. This study aimed to compare the fat, protein, and lactose content of organic and conventional raw ewe's and goat's milk in Greece and to further associate the impact of the farming practices on these parameters. Two hundred thirty-four bulk milk samples were collected from 62 goat and 16 sheep organic and conventional farms with similar farming characteristics. A standardized detailed survey and a sampling report were used in order to record the farming practices implemented in the participating farms. The chemical composition of all samples was determined by Fourier transformed infrared analysis. Statistical associations of farming practices with the milk chemical gross composition results were explored using linear mixed-model analysis. Linear mixed-model analysis revealed several factors in farming practices such as the feeding regime, the season, and the breed to be associated with ewe's and goat's milk composition, while organic or conventional farm system was not identified as an associated factor. Organic and conventional goat and sheep farming in Greece does not substantially differ, and consequently, there were no significant differences
\end{abstract}

Eleni Malissiova

malissiova@teilar.gr

1 Laboratory of Hygiene and Epidemiology, Faculty of Medicine, University of Thessaly, 41222 Larisa, Greece

2 Dairy Laboratory, Food Technology Faculty, Technological Educational Institute of Thessaly, Terma Temponera Str., 43100 Karditsa, Greece

3 Department of Agriculture Technology, Division of Animal Production, Technological Educational Institute of Epirus, 47100 Arta, Greece

4 Faculty of Agriculture, University of Thessaly, 38446 Volos, Greece

5 Faculty of Veterinary Medicine, University of Thessaly, 43100 Karditsa, Greece 
found in the examined chemical composition parameters of organic and conventional goat's and ewe's milk.

Keywords Organic $\cdot$ Milk $\cdot$ Goat $\cdot$ Ewe $\cdot$ Composition $\cdot$ Factors

\section{Introduction}

During the last decades, due to several food scandals, consumers increasingly show a preference to organic food (Banati 2011; Falguera et al. 2012). Nowadays, organic milk consumption displays an increasing trend (Sahota 2009; Liu et al. 2013) despite some concerns of the consumers related to safety and nutritional quality of the organic milk in comparison to conventional. Several studies have been published on the effect of the organic livestock management on the quality or safety characteristics of the final product, with conflicting results. Organic milk and dairy products have been reported to differ from conventional, in terms of nutritional value, while other reports claim the absence of any difference (Forman and Silverstein 2012; Palupi et al. 2012; Benbrook et al. 2013).

Organic livestock management is addressed by specific requirements, as set in the European Commission Regulation 889/2008 and the European Commission Regulation $834 / 2007$. These requirements refer to several farming practices, such as feeding regime, health management, and welfare issues. All these requirements, in Greece, are certified by private certification bodies, under the supervision of the Ministry of Rural Development and Food, through annual and unannounced audits against the relevant EU organic regulations.

Greece has a significant livestock population of sheep and goats in European Union and, consequently, produces and exports organic and conventional Feta cheese. It is worth mentioning that organic milk production in Greece presented a peak during 2007-2010, accounting for 450,000 sheep and 400,000 goats, holding the first place in Europe (EC 2010) with the potential to dominate the small ruminant sector in Greece. Thus, it is important to assess whether there are real differences in the livestock management among organic and conventional farms that may affect the final products.

Irrespectively the milk's origin (organic/conventional) and consequently certification, there are certain parameters that affect the chemical composition that should be taken into consideration, when evaluating goat's and ewe's milk nutritional quality. It is well accepted that the chemical composition of milk is substantially affected by a series of parameters such as species, breeds, lactation stage, animal's age, health, feeding regime, and the season (Jensen 1995; Chilliard and Ferlay 2004; Jenkins and McGuire 2006). So far, several studies have assessed the differences in the chemical composition of organic and conventional milk, mainly with focus on dairy cows production (Butler et al. 2008; Benbrook et al. 2013; Gabbi et al. 2013), with conflicting results (Palupi et al. 2012). Thus, there are limited studies on the nutritionally relevant compounds in goats and ewe's milk (e.g., protein, fat) focusing mainly on the organic/conventional status (Tsiplakou et al. 2010) without taking to consideration several other parameters affecting the chemical composition (e.g., seasonality, breeds, way of milking). 
This study aimed to assess the effect of detailed livestock farming practices in correlation to the type of farm (organic/conventional), on certain chemical composition parameters of goats and ewe's milk in central Greece.

\section{Material and methods}

\subsection{Study population}

Thirty-nine organic farms (31 goat farms and 8 sheep farms) participated in this study. The organic farm status was cross-checked with the Hellenic Ministry of Rural Development and Food register and additionally by the existence of a valid certificate. An equal number (31 goat farms and 8 sheep farms) of conventional farms from the same area, with animals raised under the same husbandry conditions were randomly selected for comparison purposes.

\subsection{Survey}

A standardized detailed survey was conducted for each participating farm, in order to collect data with reference to the farming system to be further analyzed as potential factors affecting milk's chemical composition. Questions were categorized in the following sections: flock characteristics (e.g., number of animals, species, breeds, milk yield), feeding (e.g., feed type, pasture type), and other farming practices (e.g., way of milking).

\subsection{Sample collection}

From December 2010 to July 2011, all 78 farms were visited in three regular intervals (start, middle, and end of the lactation period), and $500 \mathrm{~mL}$ of bulk milk was collected in sterile glass bottles. A total of 186 goat's milk samples and 48 ewe's milk samples were collected. Sampling was performed by a veterinarian, and a standardized sampling report was completed for all samples, where information was recorded (e.g., milk temperature).

\subsection{Sample composition analysis}

The chemical composition (fat, protein, and lactose) of all 234 samples was determined using a milk analyzer based on Fourier transformed infrared (FTIR) technology (MILCOSCAN-FT1-FOSS, Hillerod, Denmark). The pH was measured in all samples prior to the analysis, in order to ensure suitability $(\geq 6.5)$.

\subsection{Statistical analysis}

A database for the information collected from the sampling reports, the survey and the chemical composition results was created in Epilnfo (v.3.4.3). Statistical analysis was performed with the statistical package SPSS v.21. Quantitative variables referring to flock characteristics, which were not normally distributed, are presented as median with 
interquartile range (IQR), minimum and maximum, while qualitative variables are given as absolute frequency with percentages. Mann-Whitney test was used to explore any differences between organic and conventional flocks for quantitative variables, while Fisher's exact test was used for qualitative. Chemical composition parameters are presented as mean with standard error (SE), minimum, and maximum of untransformed data; however, protein was transformed to natural logarithm $(\ln )$ before any further analysis. Cases with outlier measures in chemical parameters were excluded from further analysis. Linear mixed-model analysis was conducted in order to identify: (a) any association among fixed factors such as farm type, breed, season, feed type, and other farming characteristics with milk chemical parameters, and (b) differences in milk chemical composition, using farming system (organic/conventional) for one-factor analysis. In both analyses, milk sampling period (season) was used as a repeated factor and the farm as the random effect. Multiple correspondence analysis and cluster analysis were used to group the nominal feed types into categories (feed type: groups 1 and 2), in order to be included as a fixed factor in the linear mixed-model analysis. Correlation analysis was performed using Spearman's rank correlation coefficient between quantitative flock characteristics to identify parameters highly correlated, in order to exclude them from the linear mixed-model analysis and consequently avoid multicollinearity. Normality of dependent variables and residuals were assessed using either KolmogorovSmirnov test or Shapiro-Wilk test without showing deviation from normality. Results were considered statistically significant when the $p \leq 0.05$.

\section{Results}

\subsection{Flocks descriptive characteristics}

A total of $83.91 \%$ of the registered organic goat and sheep farms in Thessaly were included in the present study. Organic and conventional sheep and goat farms characteristics are presented in Tables 1 and 2 for quantitative and qualitative data, respectively. Organic and conventional farms did not present any differences, with the exception of the natural pasture/head that was higher in goat organic system. In both systems, the available artificial pasture was found to be negligible in almost all farms. In order to compare the feed type used in organic and conventional goats and sheep farms, the multiple nominal recorded feed types (vetch, corn, etc.) were quantified in scores using multiple correspondence analysis (Figs. 1 and 2 for goats and sheep, respectively), and through cluster analysis, these scores were grouped (Figs. 3 and 4 for goats and sheep, respectively). Group 1 for goat's farms included oat, corn, barley, and trifolium, while group 2 included vetch, pea, wheat, and alfalfa. Similarly, group 1 for sheep farms included corn and mainly trifolium and oats, while group 2 included corn and mainly pea, wheat, and vetch. No statistically significant differences were observed when the feed type groups used in organic and conventional farms were compared (Table 2). The organic and conventional farm milk yield did not present any statistically significant difference (Tables 3 and 4). 


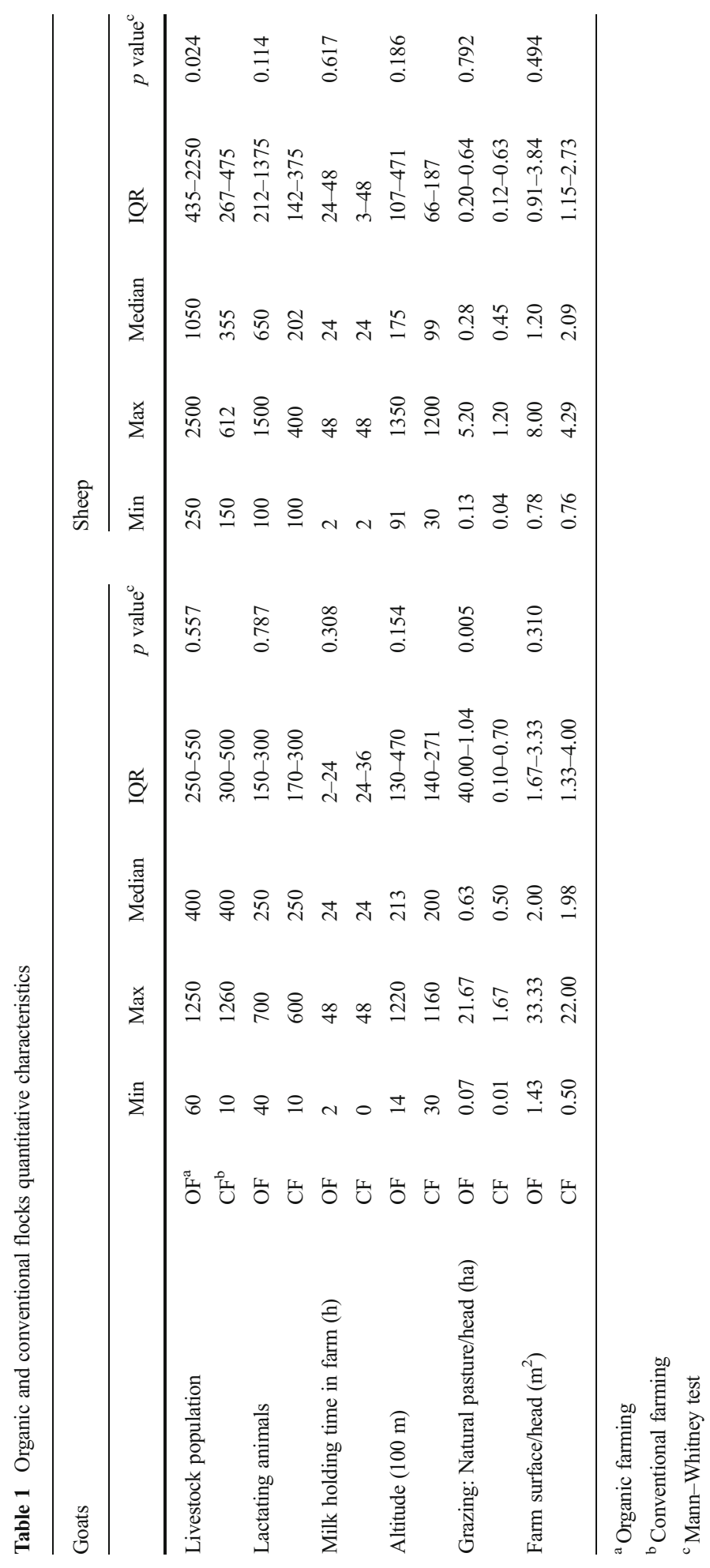


Table 2 Organic and conventional flocks qualitative characteristics

\begin{tabular}{|c|c|c|c|c|c|c|c|}
\hline \multicolumn{5}{|l|}{ Goats } & \multicolumn{3}{|l|}{ Sheep } \\
\hline & & $\mathrm{OF}^{\mathrm{a}}(n=31)$ & $\mathrm{CF}^{\mathrm{b}}(n=31)$ & & OF $(n=8)$ & $\mathrm{CF}(n=8)$ & \\
\hline & & Percent & Percent & $p$ value $^{\mathrm{c}}$ & Percent & Percent & $p$ value $^{\mathrm{c}}$ \\
\hline \multirow[t]{2}{*}{ Way of milking } & Manual & 90 & 87 & 0.999 & 50 & 50 & 0.999 \\
\hline & Automatic & 10 & 13 & & 50 & 50 & \\
\hline \multirow[t]{2}{*}{ Breed } & Native & 90 & 94 & 0.999 & 75 & 75 & 0.999 \\
\hline & Other & 10 & 6 & & 25 & 25 & \\
\hline \multirow[t]{2}{*}{ Feed type $^{\mathrm{d}}$} & Group 1 & 87 & 97 & 0.354 & 75 & 75 & 0.999 \\
\hline & Group 2 & 13 & 3 & & 25 & 25 & \\
\hline
\end{tabular}

${ }^{\text {a } O r g a n i c ~ f a r m i n g ~}$

${ }^{\mathrm{b}}$ Conventional farming

${ }^{\mathrm{c}}$ Fisher's exact test

${ }^{\mathrm{d}}$ Group 1 for goats: oat, corn, barley, trifolium; group 2 for goats: vetch, pea, wheat, alfalfa; group 1 for sheep: corn and mainly trifolium, oats; group 2 for sheep: corn and mainly pea, wheat, vetch

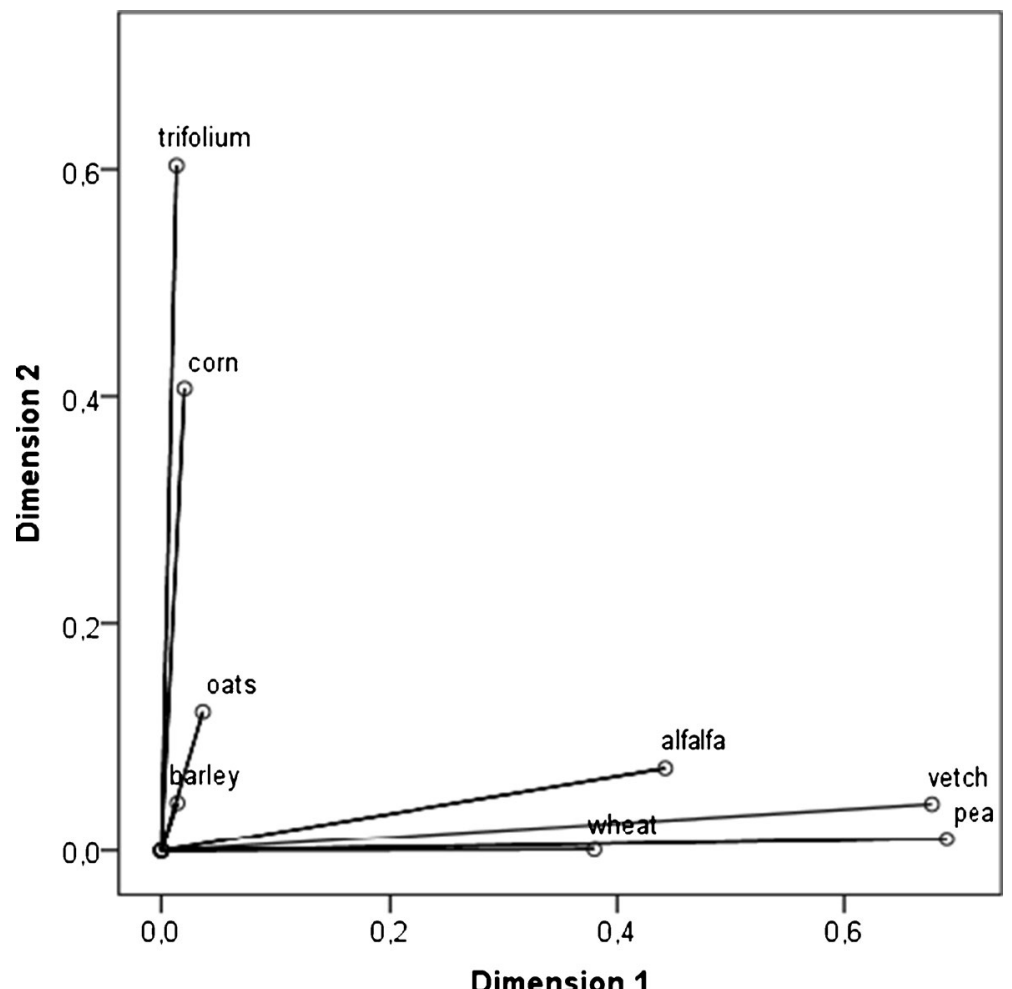

Fig. 1 Discrimination measures of multiple correspondence analysis for feed types used for goats farms. Group 1: oats, corn, barley, trifoliu; group 2: vetch, pea, wheat, alfalfa 


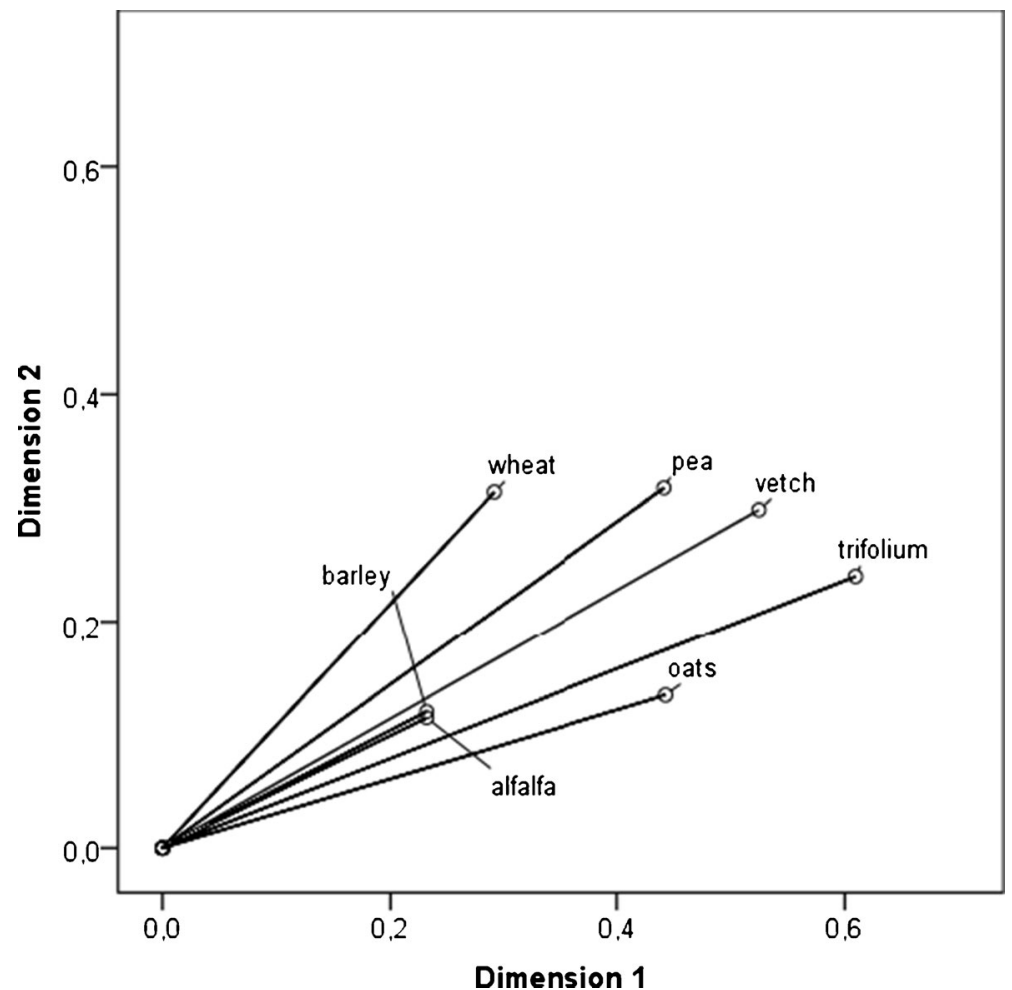

Fig. 2 Discrimination measures of multiple correspondence analysis for feed types used for sheep farms. Group 1: corn and mainly trifolium, oats; group 2: corn and mainly pea, wheat, vetch

\subsection{Chemical composition of goat's and ewe's milk samples}

Statistically significant differences were not identified in protein and lactose concentration when comparing goat's organic and conventional milk samples (Table 3), while higher concentrations of fat $(p=0.004)$ was found in organic milk. Lactose content in organic goat's milk presented a tendency $(p=0.064)$ to be higher in comparison to conventional. Ewe's organic and conventional milk did not present any statistically significant difference in relation to the chemical composition parameters assessed (Table 4).

\subsection{Farming characteristics affecting goat's and ewe's milk compositional profile}

An effort was made to assess how different farming practices affect the chemical composition of the milk samples. The linear mixed model (multivariate analysis) implemented revealed for goat's milk (Table 5) that fat was positively associated to the farm altitude. Higher value of fat content was also associated with feeding type group 2 and with winter season. Goat's milk protein was positively associated to winter and spring season. Higher value of lactose content in goat's milk was associated to winter and spring season and to other than native breeds. Regarding ewe's milk (Table 6), the linear mixed model used revealed that fat was negatively associated with 


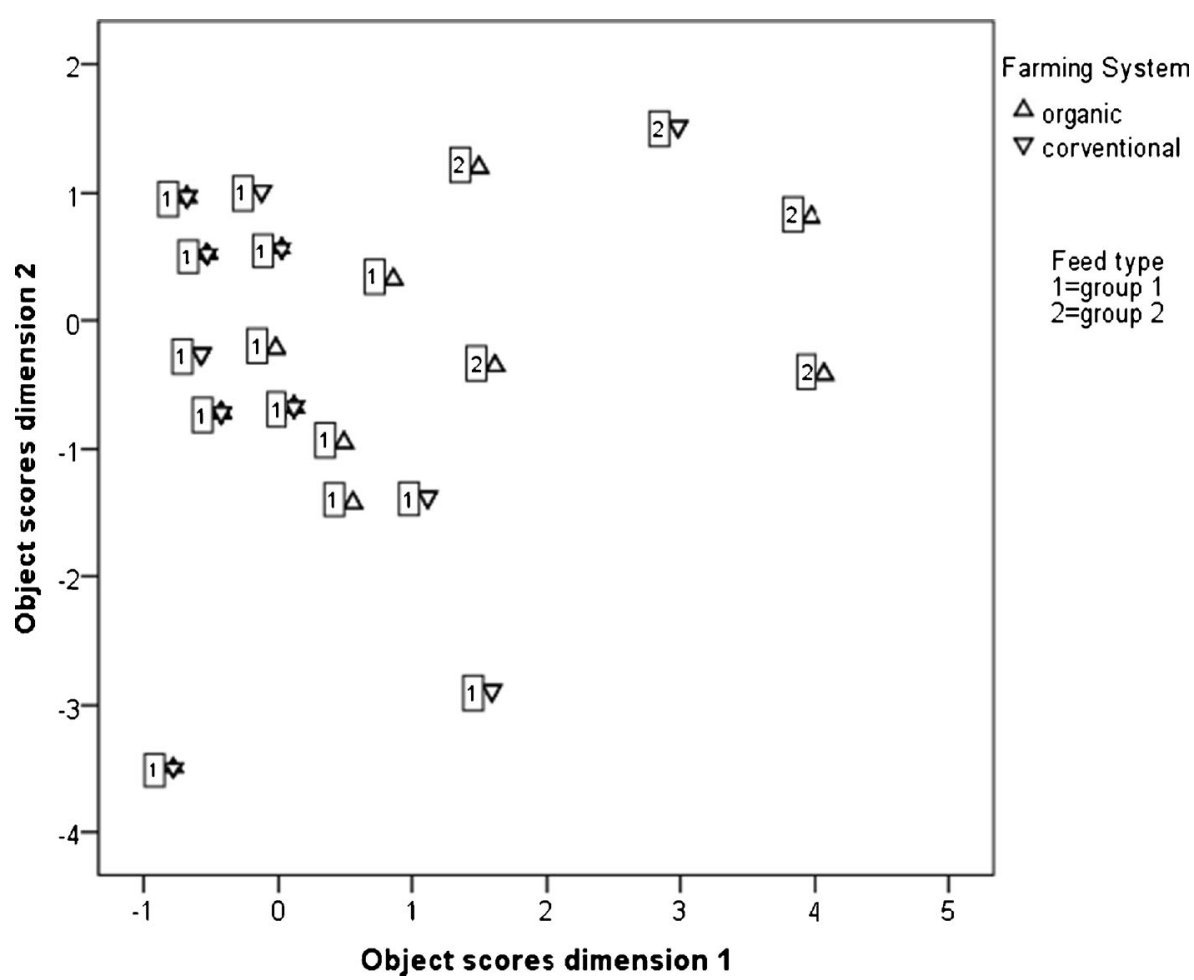

Fig. 3 Cluster analysis for feed types used for goats farms in organic and conventional farming. Group 1: oats, corn, barley, trifolium; group 2: vetch, pea, wheat, alfalfa. The feed type scores of the 62 farms, as concluded by the MCA, are presented in 18 points, taking into consideration the group of feed types (groups 1 and 2) and also the farming system (organic and conventional)

the milk holding time at the farm and the milk yield. Lower value of protein content in ewe's milk was associated with the winter season, native breeds, and the milk holding time. Ewe's milk lactose was found to be associated with all factors, excluding the farming system and the milk holding time at the farm, while only winter and spring season and the available natural pasture per head were positively associated with lactose.

\section{Discussion}

The effects of production system (organic and conventional) on nutritionally relevant milk quality parameters (protein, fat and lactose) were assessed taking into consideration a series of possible confounders for commercial goat's and ewe's dairy production systems in Central Greece for the first time. The comparison among the farming systems did not reveal any significant differences, with the exception that organic goats had more available natural pasture per head. Additionally, the cluster analysis conducted for the feed types used in all farms revealed similarities, identifying two groups that included both concentrated feeds and forages. An important finding was also that organic and conventional farms milk yield did not present any statistically significant 


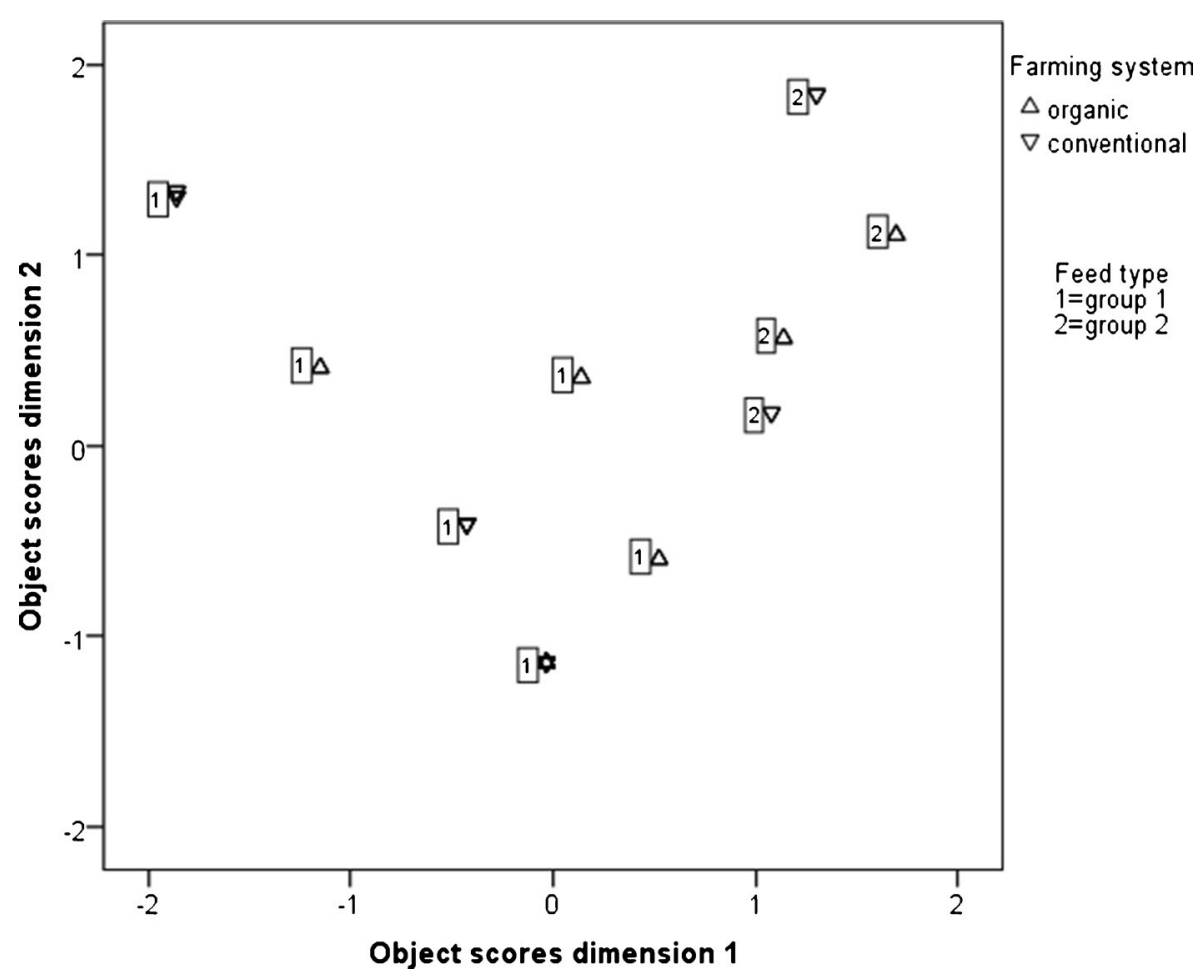

Fig. 4 Cluster analysis for feed types used for sheep farms in organic and conventional farming. Group 1: corn and mainly trifolium, oats; group 2: corn and mainly pea, wheat, vetch. The feed type scores of the 16 farms, as concluded by the MCA, are presented in 10 points, taking into consideration the group of feed types (group1 and 2) and also the farming system (organic and 361 conventional)

difference. The reason that we did not identify substantial differences among organic and conventional farms might be that the characteristic semi-extensive systems that prevail in sheep and goat production in Greece are possibly well fitted in the organic farming requirements, as reported by others (Arsenos et al. 2003). Even if the restricted geographical area where the samples were collected may limit the generalizability of the results, it has to be considered that that area is a predominantly rural area with high livestock numbers and milk yield, able to significantly affect Greek milk production.

Table 3 Organic and conventional goat's milk samples chemical composition

\begin{tabular}{|c|c|c|c|c|c|c|c|c|c|}
\hline \multicolumn{5}{|l|}{ Organic $(n=93$} & \multicolumn{5}{|c|}{ Conventional $(n=93)$} \\
\hline & Minimum & Maximum & Mean & $\mathrm{SE}^{\mathrm{a}}$ & Minimum & Maximum & Mean & $\mathrm{SE}^{\mathrm{a}}$ & $p$ value \\
\hline Fat $(\%)$ & 4.94 & 5.34 & 5.14 & 0.10 & 4.52 & 4.91 & 4.72 & 0.09 & 0.004 \\
\hline Protein $(\%)$ & 3.60 & 3.74 & 3.67 & 0.04 & 3.55 & 3.70 & 3.62 & 0.04 & 0.370 \\
\hline Lactose $(\%)$ & 4.54 & 4.62 & 4.58 & 0.02 & 4.49 & 4.57 & 4.53 & 0.02 & 0.064 \\
\hline Milk yield $(\mathrm{kg})^{\mathrm{b}}$ & 0.33 & 1.90 & 0.947 & 0.07 & 0.28 & 1.83 & 1.08 & 0.07 & 0.206 \\
\hline
\end{tabular}

\footnotetext{
${ }^{\text {a }}$ Standard error

${ }^{\mathrm{b}}$ Milk production/head/day
} 
Table 4 Organic and conventional ewe's milk samples chemical composition

\begin{tabular}{|c|c|c|c|c|c|c|c|c|c|}
\hline \multicolumn{5}{|l|}{ Organic $(n=24)$} & \multicolumn{5}{|c|}{ Conventional $(n=24)$} \\
\hline & Minimum & Maximum & Mean & $\mathrm{SE}^{\mathrm{a}}$ & Minimum & Maximum & Mean & $\mathrm{SE}^{\mathrm{a}}$ & $p$ value \\
\hline Fat $(\%)$ & 5.51 & 6.61 & 6.06 & 0.26 & 5.86 & 6.95 & 6.41 & 0.25 & 0.358 \\
\hline Protein (\%) & 5.15 & 5.59 & 5.37 & 0.10 & 5.27 & 5.71 & 5.49 & 0.10 & 0.437 \\
\hline Lactose $(\%)$ & 4.65 & 4.85 & 4.75 & 0.05 & 4.55 & 4.75 & 4.65 & 0.05 & 0.156 \\
\hline Milk yield $(\mathrm{kg})^{\mathrm{b}}$ & 0.37 & 1.85 & 0.91 & 0.18 & 0.36 & 1.85 & 1.01 & 0.19 & 0.696 \\
\hline
\end{tabular}

${ }^{\text {a }}$ Standard error

${ }^{\mathrm{b}}$ Milk production/head/day

Regarding the compositional parameters of organic milk, this study indicated that there is statistically significant difference in fat levels in goat's milk, when comparing organic to conventional. Additionally, lactose content presented a tendency to significantly differ among organic and conventional goat milk. In any case, as these results are based on one-factor analysis, it will not be possible to draw conclusions without taking under consideration other associated factors. This is also apparent by the diversity in the literature on this issue; differences in relation to fat have been reported by Tsiplakou et al. (2010) in organic sheep and goat milk and Stergiadis et al. (2012) and Benbrook et al. (2013) in organic cow's milk, while other researchers reported that they did not identify substantial differences regarding the chemical composition of organic and conventional milk (Toledo et al. 2002). Nevertheless, a longer monitoring period, or even a higher number of samples, may facilitate to improve borderline statistic associations.

In order to control for confounders, we used a linear mixed model (multivariate analysis), taking into consideration several associated factors to milk's composition. This analysis indicated that nearly all factors included in the model affected at least one chemical component of ewe's and goat's milk. Moreover, it was identified that the farming system (conventional/organic) was not statistically associated with the milk chemical composition, either for goat's or ewe's milk. These results are considered more informative in comparison to the univariate analysis, and thus, we can conclude that there is no difference on nutritional components of organic and conventional goat's and ewe's milk. This main finding is possibly due to the fact that organic and conventional sheep and goat farms do not substantially differ in Greece in the studied sample dataset.

The multivariate analysis conducted revealed several factors having an impact on the gross composition of organic goats and ewes milk, irrespective of the type of farm. More specifically, season was a parameter with great impact on on goat's and ewe's milk composition, as reported by others (Nateghi et al. 2014; Butler et al. 2008). In Greece, lambing or kidding are synchronized in the same period of the year; therefore, the flock has all the animals at the same lactation stage, and samples were collected at three different seasons (winter, spring, and summer). Different stages of lactation may be correlated with differences in milk composition (Morand-Fehr et al. 2007). Furthermore, the seasonal differences may be also related to the different feeding regimes that need to be followed (Jensen 1995). Additionally, this study focused on the type of feeds 


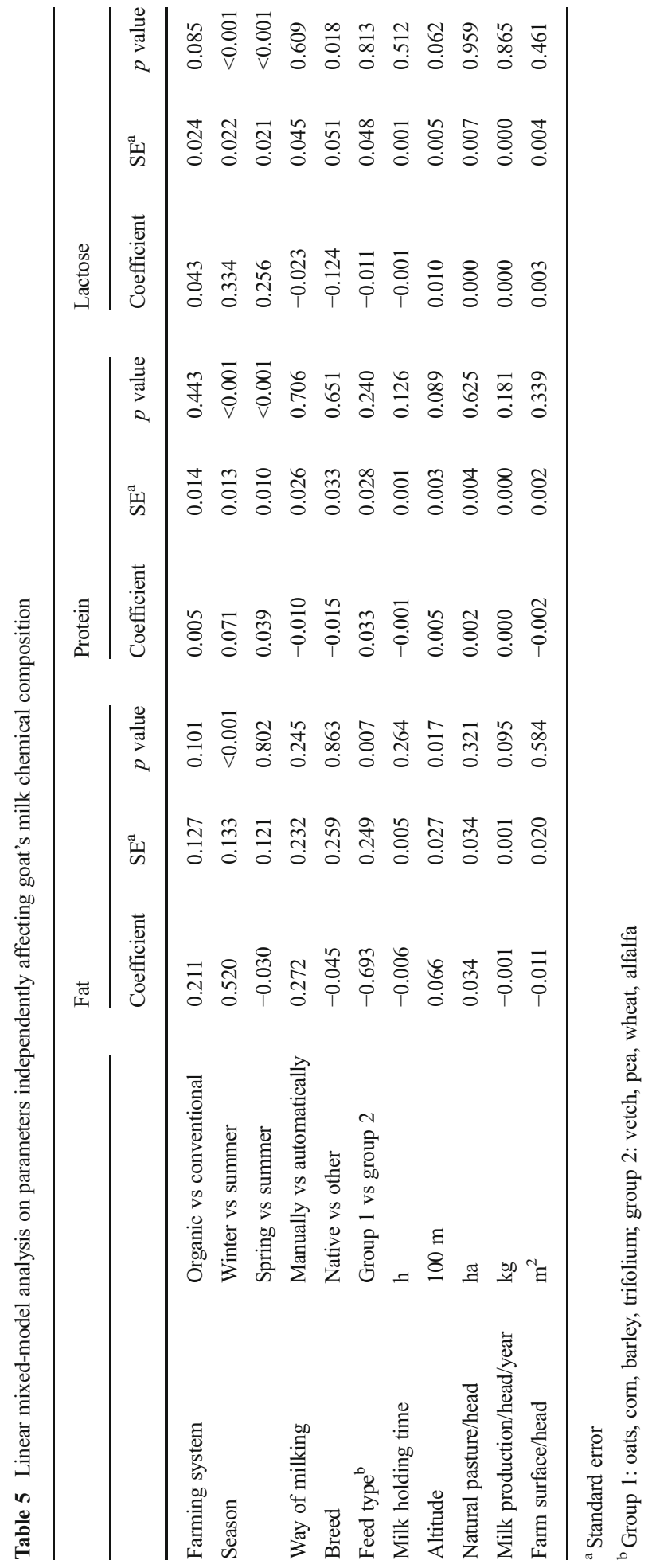




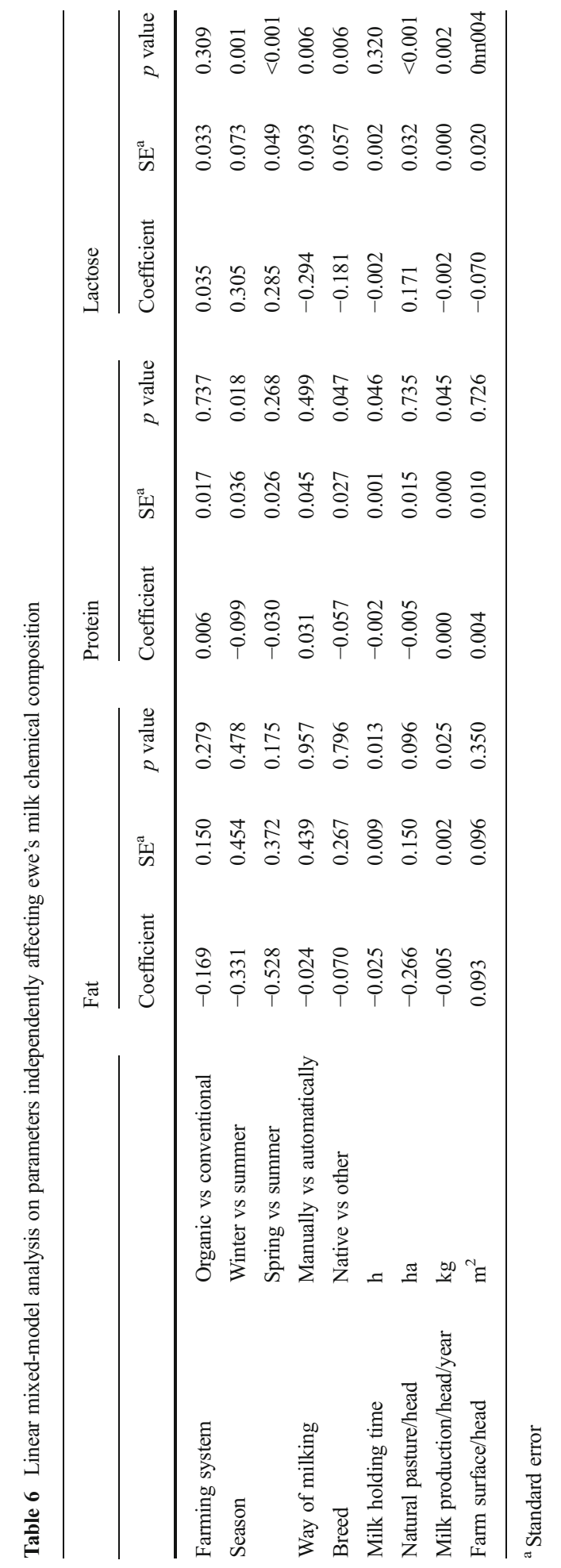


used and also on the forage type (natural/artificial pastures). The available pasture/head was positively associated with the levels of lactose in ewe's milk. Grazing on natural pasture is related to higher amount of nutrient components in milk (Morand-Fehr et al. 2007; Nateghi et al. 2014). Goat's milk was found to be higher in fat when certain feed type (e.g., vetch, wheat) was used. Similar results were found in other studies (Zervas and Tsiplakou 2011).

Other factors identified to be associated with milk gross chemical composition in the multivariate analysis include the use of native breeds, the way of milking, and milk holding time at farm. More specifically, lactose and protein contents were found to be higher in milk from other than native breeds. This may be related to mammary gland differences among breeds, such as anatomic particularities and different morphological patterns (Cadar et al. 2012; Lerias et al. 2014). Manual milking was associated with lower lactose content in ewe's milk. This could be related to a possible increase in the frequency of mastitis cases with manual milking (Leitner et al. 2004). The milk holding time was also found to be negatively associated with fat and protein levels in ewe's milk, implying that prolonged storage of milk at farm level affects compositional parameters. During long-term cold storage of raw milk, low temperatures induce changes in almost all of its components, while the concurrent vibration provokes intensive lipolytic and proteolytic processes (Czerniewicz et al. 2006; White 2003).

\section{Conclusion}

This study provides new evidence for the hypothesis that organic ewe's and goat's milk in Greece does not induce nutritional differences to conventional, as there are similarities in the production systems and also there are several other factors, such as season, feed types, and breeds, which may affect the concentrations of nutritionally desirable compounds in milk, irrespective of the organic or conventional farm status.

Acknowledgments We extend thanks to all the farmers and veterinary officers involved for their cooperation during the study.

Conflict of interest The authors E. Malissiova, A. Tzora, A. Katsioulis, M. Hatzinikou, A. Tsakalof, I.S. Arvanitoyannis, A. Govaris, and C. Hadjichristodoulou declare that they have no conflict of interest.

Compliance with ethics requirement statements This article does not contain any studies with human or animal subjects performed by any of the authors.

\section{References}

Arsenos G, Fortomaris P, Banos G, Zygoyiannis D (2003) Current practice and prospects of organic livestock production in Greece. Proceedings of the 1st workshop on "Socio-Economic Aspects of Animal Health and Food Safety in Organic Farming Systems". UK: The University of Reading

Banati D (2011) Consumer response to food scandals and scares. Trends Food Sci Technol 22:56-60

Benbrook C, Butler G, Latif A, Leifert C, Davis D (2013) Organic production enhances milk nutritional quality by shifting fatty acid composition: a United States-wide, 18-month study. PLoS ONE 8(12):1-13

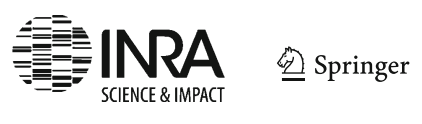


Butler G, Nielsen JH, Slots T, Seal C, Eyre MD, Sanderson R, Leifert C (2008) Fatty acid and fat-soluble antioxidant concentrations in milk from high- and low-input conventional and organic systems: seasonal variation. J Sci Food Agric 88:1431-1441

Cadar M, Mireșan V, Lujerdean A, Raducu C (2012) Mammary gland histological structure in relation with milk production in sheep. J Anim Sci Biotechnol 45(2):144-148

Chilliard Y, Ferlay A (2004) Dietary lipids and forages interactions on cow and goat milk fatty acid composition and sensory properties. Reprod Nutr Dev 44:467-492

Czerniewicz M, Kruk A, Kieczewska K (2006) Storage stability of raw milk subjected to vibration. Pol J Food Nutr Sci 15/56(SI 1):65-70

European Commission (2010) An analysis of the EU organic sector European Commission, Agriculture and Rural Development, Belgium. http://ec.europa.eu/agriculture/analysis/markets/organic_2010_en.pdf. Accessed 4 April 2012

Falguera V, Aliguer N, Falguera M (2012) An integrated approach to current trends in food consumption: moving toward functional and organic products? Food Control 26:274-281

Forman J, Silverstein J (2012) Organic foods: health and environmental advantages and disadvantages. Pediatrics 130:1406-1415

Gabbi AM, McManus CM, Silva AV, Marques LT, Zanela MB, Stumpf MP, Fischer V (2013) Typology and physical-chemical characterization of bovine milk produced with different productions strategies. Agric Syst 121:130-134

Jenkins TC, McGuire MA (2006) Major advances in nutrition: impact on milk composition. J Dairy Sci 89(4): 1302-1310

Jensen RG (1995) Handbook of milk composition. Academic Press, UK

Leitner G, Chaffer M, Shamay A, Shapiro F, Merin U, Ezra E, Saran A, Silanikove N (2004) Changes in milk composition as affected by subclinical mastitis in sheep. J Dairy Sci 87:46-52

Lerias JR, Hernandez-Castellano LE, Suarez-Trujillo A, Castro N, Pourlis A, Almeida AM (2014) The mammary gland in small ruminants: major morphological and functional events underlying milk production-a review. J Dairy Res 81(3):304-318

Liu Z, Kanter CA, Messer KD, Kaiser HM (2013) Identifying significant characteristics of organic milk consumers: a CART analysis of an artefactual field experiment. Appl Econ 45(21):3110-3121

Morand-Fehr P, Fedele V, Decandia M, Le Frileux Y (2007) Influence of farming and feeding systems on composition and quality of goat and sheep milk. Small Rumin Res 68(1-2):20-34

Nateghi L, Yousefi M, Zamani E, Gholamian M, Mohammadzadeh M (2014) The effect of different seasons on the milk quality. Eur J Exp Biol 4(1):550-552

Palupi E, Jayanegara A, Ploeger A, Kahl J (2012) Comparison of nutritional quality between conventional and organic dairy products: a meta-analysis. J Sci Food Agric 92(14):2774-2781

Sahota A (2009) The global market for organic food and drink. In: Willer H, Klicher L (eds) The world of organic agriculture: statistics and emerging trends. FiBL-IFOAM, Frick

Stergiadis S, Leifert C, Seal CJ, Eyre MD, Nielsen JH, Larsen MK, Slots T, Steinshamn H, Butler G (2012) Effect of Feeding Intensity and Milking System on Nutritionally Relevant Milk Components in Dairy Farming Systems in the North East of England. J Agric Food Chem 60:7270-7281

Toledo P, Andrlen A, Bjorck L (2002) Composition of raw milk from sustainable production systems. Int Dairy J 12:75-80

Tsiplakou E, Kotrotsios V, Hadjigeorgiou I, Zervas G (2010) Differences in sheep and goats milk fatty acid profile between conventional and organic farming systems. J Dairy Res 77(3):343-349

White CH (2003) Effects of storage and transport on milk quality. In: Roginski H (ed) Encyclopedia of dairy sciences. Academic Press Elsevier Science Ltd, Amsterdam

Zervas G, Tsiplakou E (2011) The effect of feeding systems on the characteristics of products from small ruminants. Small Rumin Res 101:140-149 